\title{
A Comparative Study on Drivers' Stop/Go Behavior at Signalized Intersections Based on Decision Tree Classification Model
}

\author{
Sheng Dong ${ }^{1}$ and Jibiao Zhou $\mathbb{D i D}^{2,3}$ \\ ${ }^{1}$ School of Civil and Transportation Engineering, Ningbo University of Technology, Fenghua Rd. \#201, Jiangbei District, Ningbo, \\ Zhejiang 315211, China \\ ${ }^{2}$ Department of Transportation Engineering, Tongji University, Caoan Rd. \#4800, Shanghai 201804, China \\ ${ }^{3}$ Intelligent Transport System (ITS) RङD Center, Shanghai Urban Construction Design and Research Institute (Group) Co., Ltd., \\ Shanghai 200082, China
}

Correspondence should be addressed to Jibiao Zhou; zhoujibiao@tongji.edu.cn

Received 27 December 2019; Revised 3 February 2020; Accepted 12 May 2020; Published 29 May 2020

Academic Editor: Qiang Zeng

Copyright ( 2020 Sheng Dong and Jibiao Zhou. This is an open access article distributed under the Creative Commons Attribution License, which permits unrestricted use, distribution, and reproduction in any medium, provided the original work is properly cited.

The stop/go decisions at signalized intersections are closely related to driving speed during signal change intervals. The speed during stop/go decision-making has a significant influence on the dilemma area, resulting in changes of stop/go decisions and high complexity of the decision-making process. Considering that traffic delays and vehicle exhaust pollution are mainly caused by queuing at intersections, the stop-line passing speed during the signal change interval will affect both vehicle operation safety and the atmospheric environment. This paper presents a comparative study on drivers' stop/go behaviors when facing a transition signal period consisting of $3 \mathrm{~s}$ green flashing light $(\mathrm{FG})$ and $3 \mathrm{~s}$ yellow light $(\mathrm{Y})$ at rural high-speed intersections and urban intersections. For this study, 1,459 high-quality vehicle trajectories of five intersections in Shanghai during the transition signal period were collected. Of these five intersections, three are high-speed intersections with a speed limit of $80 \mathrm{~km} / \mathrm{h}$, and the other two are urban intersections with a speed limit of $50 \mathrm{~km} / \mathrm{h}$. Trajectory data of these vehicle samples were statistically analyzed to investigate the general characteristics of potential influencing factors, including the instantaneous speed and the distance to the intersection at the start of FG, the vehicle type, and so on. Decision Tree Classification (DTC) models are developed to reveal the relationship between the drivers' stop/go decisions and these possible influencing factors. The results indicate that the instantaneous speed of FG onset, the distance to the intersection at the start of FG, and the vehicle type are the most important predictors for both types of intersections. Besides, a DTC model can offer a simple way of modeling drivers' stopping decision behavior and produce good results for urban intersections.

\section{Introduction}

At signalized intersections in most cities of China, a 3 s green flashlight (FG) indicator and a $3 \mathrm{~s}$ yellow light $(\mathrm{Y})$ indicator are the most common form of transition signal setting [1-3]. The current practice shows that it is reasonable to set the yellow light as $3 \mathrm{~s}$ for the intersection with a speed limit of less than $50 \mathrm{~km} / \mathrm{h}$. Once the speed limit is higher than $50 \mathrm{~km} /$ $\mathrm{h}$, the vehicle will often fall into the dilemma zone (DZ) due to the higher driving speed and insufficient yellow light duration [4-8]. In most Chinese cities, the speed limit of high-speed intersections in rural areas is generally larger than $60 \mathrm{~km} / \mathrm{h}$. In comparison, in urban areas, the speed limit of high-speed intersections is usually smaller than $60 \mathrm{~km} / \mathrm{h}$. Thus, for the above two intersections with different areas, the setting of green flashlight (FG) can impose other effects on the stop/go decision-making behavior of drivers.

Tremendous research efforts have done to study the influence of FG on drivers' decision-making behaviors as well as to model such behaviors in response to signal change intervals. However, few studies have compared the impact of FG on the driver decision-making process at different types of intersections. Furthermore, there is no study on the specific combination of 3-second yellow light $(\mathrm{Y})$ and 3second green flashlight (FG). This kind of signal combination is a unique feature of signalized intersections in 
TABLE 1: Characteristics and conditions of the investigated intersections.

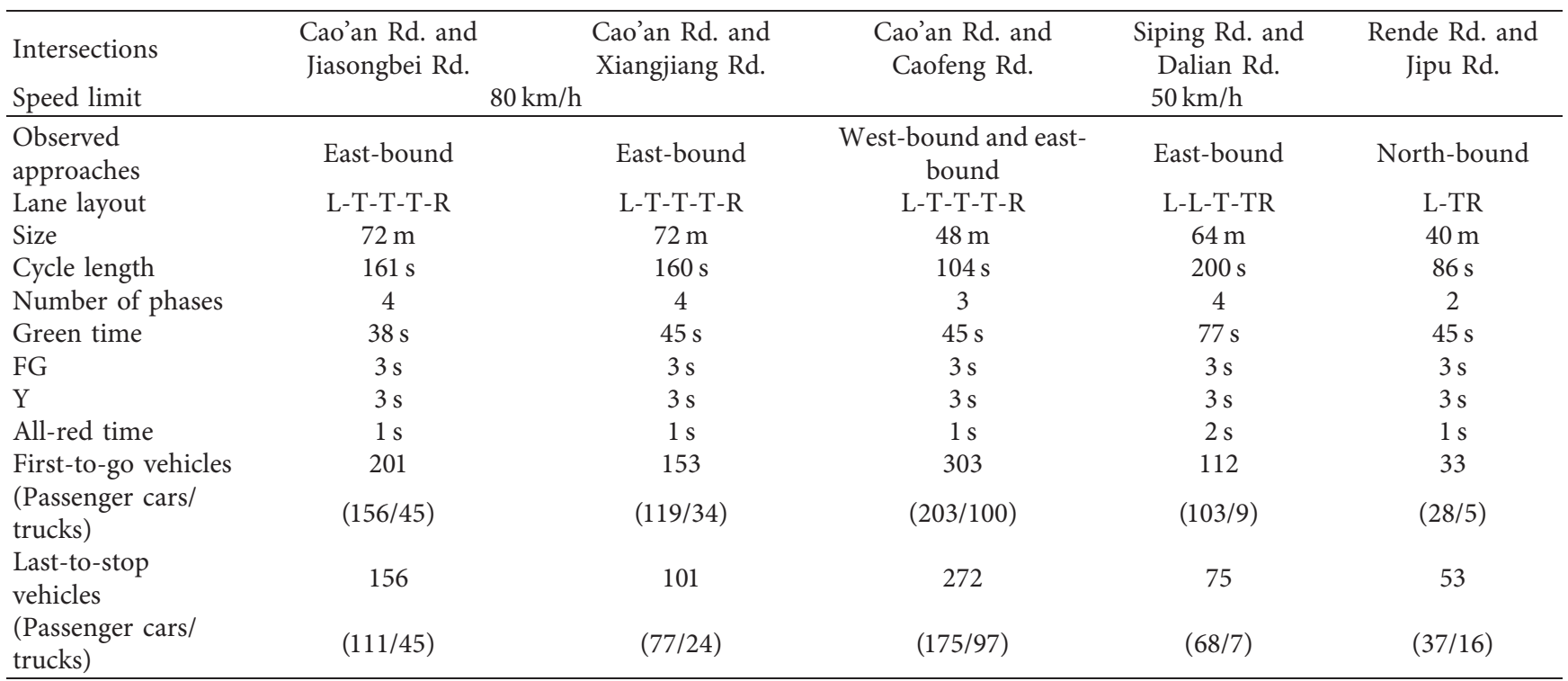

Note: $\mathrm{L}=$ exclusive left-turn lane; $\mathrm{T}=$ through-ahead lane; $\mathrm{R}=$ exclusive right-turn lane; $\mathrm{TR}=$ shared through and right-turn lane.

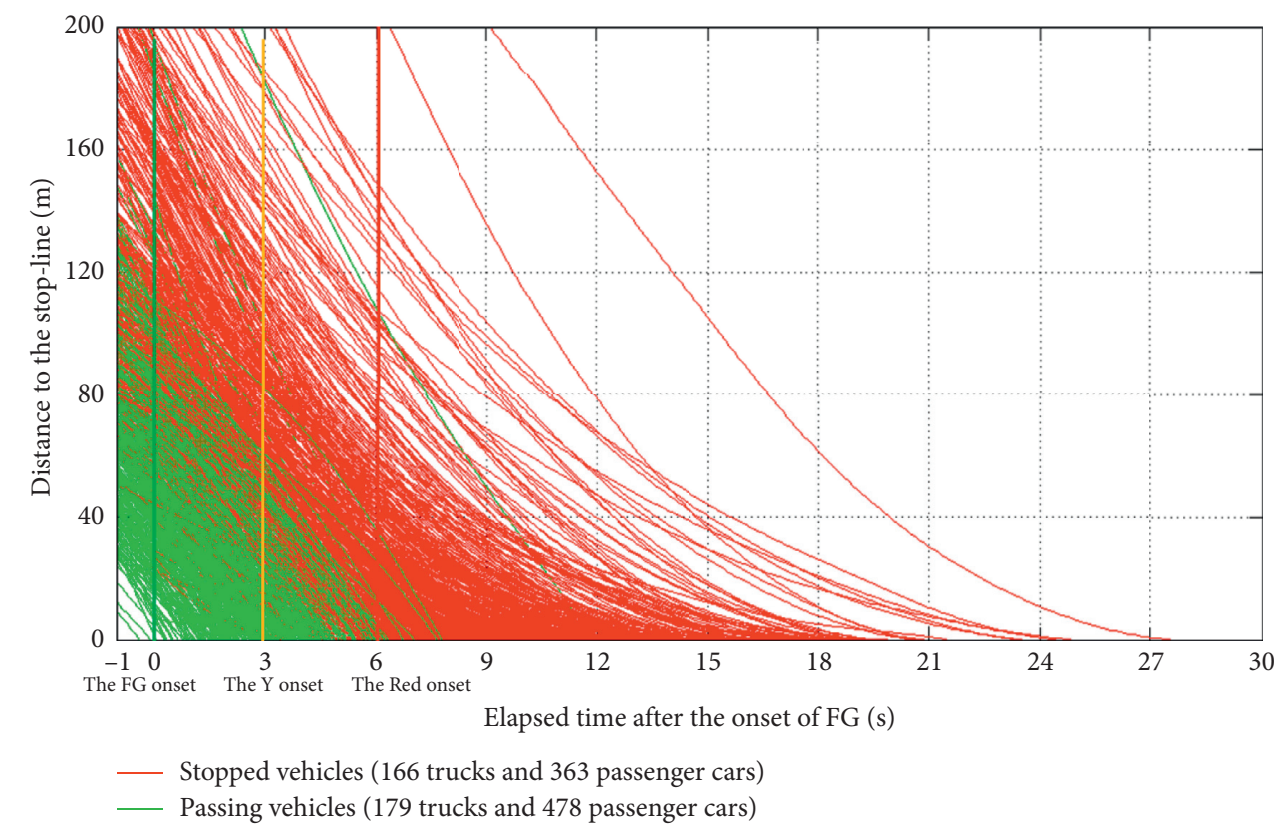

(a)

Figure 1: Continued. 


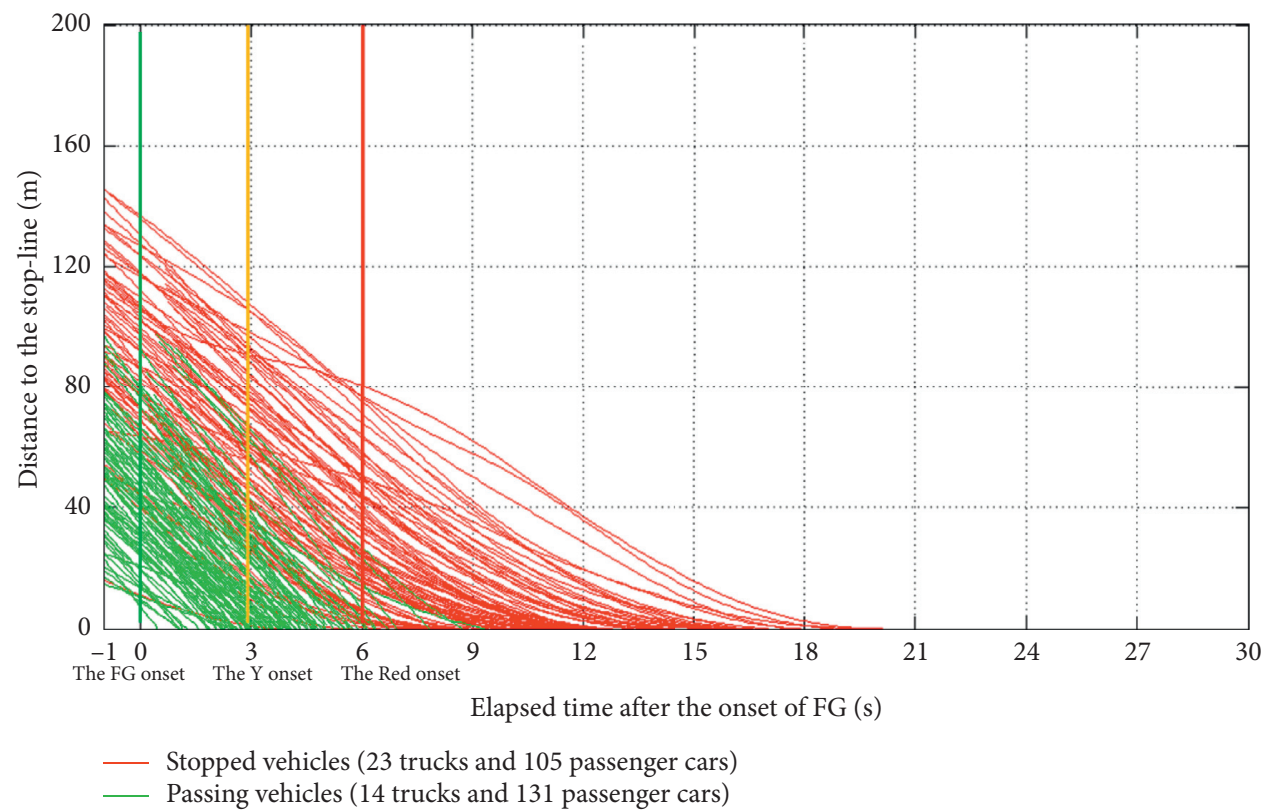

(b)

Figure 1: Vehicle trajectory data of the investigated intersections. (a) Rural intersections (the speed limit is $80 \mathrm{~km} / \mathrm{h}$ ) and (b) urban intersections (the speed limit is $50 \mathrm{~km} / \mathrm{h}$ ).

TABle 2: Descriptive statistics for instantaneous speed at the onset of FG (unit: $\mathrm{km} / \mathrm{h}$ ).

\begin{tabular}{|c|c|c|c|c|c|c|c|}
\hline Intersection types & Sublevel & Sublevel & Sample size & Mean & Std. dev & Min & Max \\
\hline \multirow{6}{*}{ Rural intersections } & \multirow{3}{*}{ Stop } & Passenger cars & 363 & 61.8 & 19.1 & 16.7 & 118.9 \\
\hline & & Trucks & 166 & 53.8 & 17.4 & 21.7 & 115.6 \\
\hline & & Overall & 529 & 59.3 & 18.9 & 16.7 & 118.9 \\
\hline & \multirow{3}{*}{ Go } & Passenger cars & 478 & 64.5 & 16.7 & 19.4 & 115 \\
\hline & & Trucks & 179 & 56.1 & 15.6 & 5.6 & 100.6 \\
\hline & & Overall & 657 & 62.2 & 16.8 & 5.6 & 115 \\
\hline \multirow{6}{*}{ Urban intersections } & \multirow{3}{*}{ Stop } & Passenger cars & 105 & 39.2 & 8.9 & 16.4 & 64.5 \\
\hline & & Trucks & 23 & 38.9 & 8.1 & 23.3 & 56.2 \\
\hline & & Overall & 128 & 39.2 & 8.7 & 16.4 & 64.5 \\
\hline & \multirow{3}{*}{ Go } & Passenger cars & 131 & 45.4 & 10.3 & 15.2 & 68 \\
\hline & & Trucks & 14 & 46.6 & 8.7 & 21.4 & 57.2 \\
\hline & & Overall & 145 & 45.5 & 10.2 & 15.2 & 68 \\
\hline
\end{tabular}

China. It provides a long time for the observation and determination of the driver before stop/go decision-making, i.e., $6 \mathrm{~s}$. Therefore, this paper mainly focuses on the research gap.

In this study, the Decision Tree Classification (DTC) models are applied to analyze how drivers' stop decisions relate to potential influencing factors for two different types of intersections. Firstly, vehicle trajectory data, reflecting stop/go decision behavior of five intersections, are collected during the signal change interval. Three of which are highspeed intersections with a speed limit of $80 \mathrm{~km} / \mathrm{h}$ in the rural area, and two of which are intersections with a speed limit of $50 \mathrm{~km} / \mathrm{h}$ in the urban area. Secondly, we use these trajectory data, and we also carried out statistical analysis to summarize the general characteristics of the potential influencing factors of the two types of the intersection, including instantaneous speed, the vehicle type, and the distance to the intersection at the beginning of FG signal. Thirdly, the DTC model is built based on the description of the critical design decisions and parameters. Next, the results of the DTC model and the discussion of findings are given accordingly. Finally, we summarize the findings of the study, point out the contribution of this study, and suggest future directions of related research.

\section{Literature Review}

Many previous achievements have focused on the influence of FG on the driver's decision behavior and DZ. There are both positive and negative conclusions about the effect of FG in these kinds of literature studies. The positive results show that FG can warn the driver that the phase of green light is 


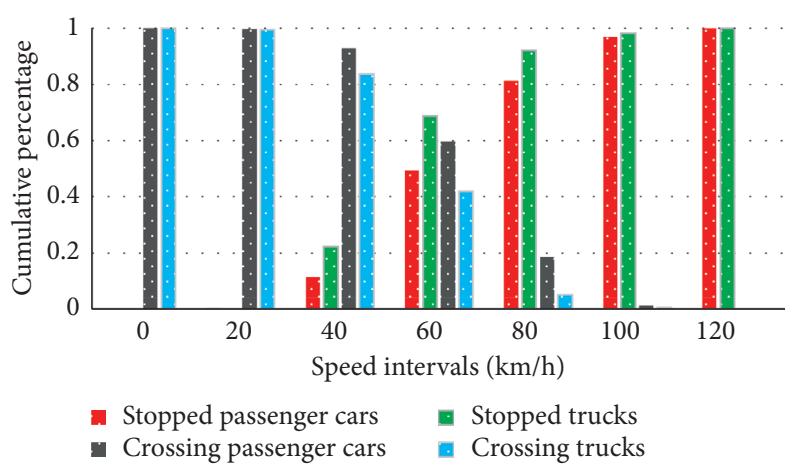

(a)

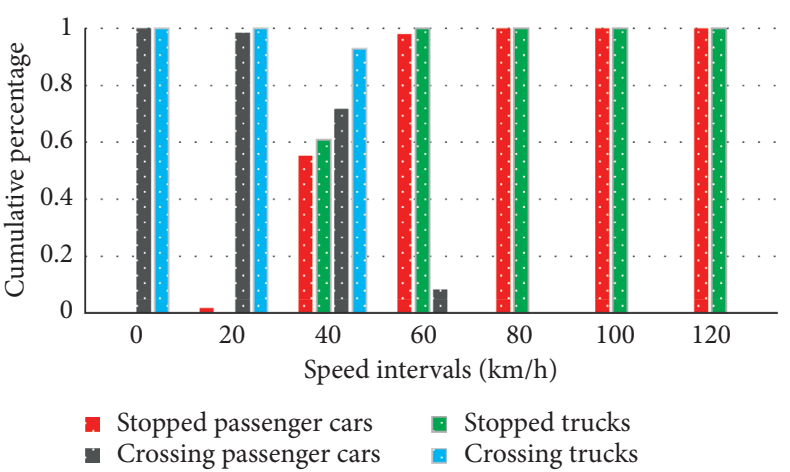

(b)

FIgURE 2: Stop/go decision distribution based on speed intervals. (a) Rural intersections and (b) urban intersections.

TABLE 3: Descriptive statistics for distance to the intersection at the beginning of FG (unit: $\mathrm{m}$ ).

\begin{tabular}{|c|c|c|c|c|c|c|c|}
\hline Intersection types & Sublevel & Sublevel & \# & Mean & Std. dev & Min & Max \\
\hline \multirow{6}{*}{ Rural intersections } & \multirow{3}{*}{ Stop } & Passenger cars & 363 & 105.9 & 37.6 & 23.1 & 217.7 \\
\hline & & Trucks & 166 & 102.5 & 36.5 & 23.6 & 197.5 \\
\hline & & Overall & 529 & 104.8 & 37.2 & 23.1 & 217.7 \\
\hline & \multirow{3}{*}{ Go } & Passenger cars & 478 & 56.4 & 26.4 & 3.2 & 132.9 \\
\hline & & Trucks & 179 & 49.3 & 26.5 & 5.2 & 132.9 \\
\hline & & Overall & 657 & 54.5 & 26.6 & 3.2 & 132.9 \\
\hline \multirow{6}{*}{ Urban intersections } & \multirow{3}{*}{ Stop } & Passenger cars & 105 & 95.7 & 24.9 & 39.8 & 163.1 \\
\hline & & Trucks & 23 & 96.7 & 35.5 & 40.4 & 155.6 \\
\hline & & Overall & 128 & 95.8 & 26.9 & 39.8 & 163.1 \\
\hline & \multirow{3}{*}{ Go } & Passenger cars & 131 & 46.2 & 19.5 & 7.5 & 95.2 \\
\hline & & Trucks & 14 & 60.3 & 23.3 & 16.7 & 97.7 \\
\hline & & Overall & 145 & 47.6 & 20.2 & 7.5 & 97.7 \\
\hline
\end{tabular}

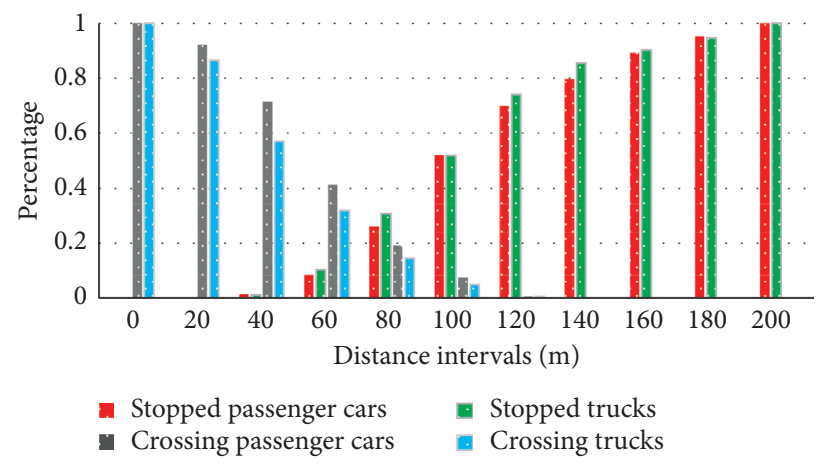

(a)

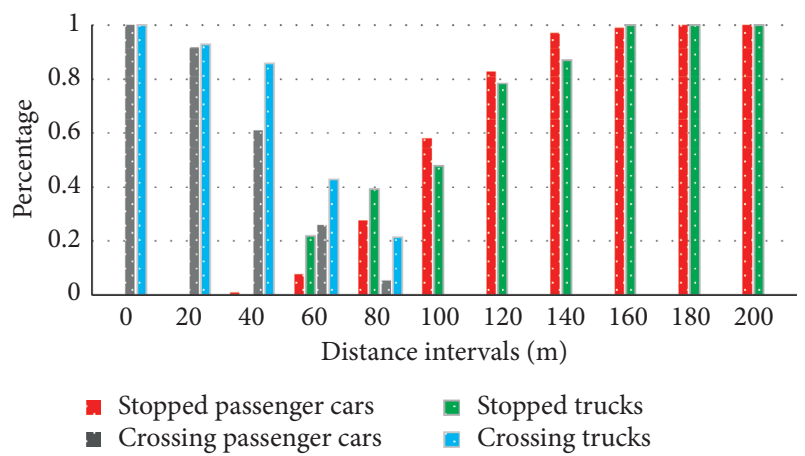

(b)

FIgURe 3: Distributions of stop/go decisions for distance interval from intersections. (a) Rural intersections and (b) urban intersections.

coming to an end, and the driver can reduce the incidence of DZ by reducing the driving speed, to avoid red light violations $[1,2,9]$. FG signal essentially plays a role in prolonging the duration of yellow light. Therefore, compared with the intersections without FG, the proportion of drivers running the red light at the intersections with FG is significantly reduced [10-13]. Among the negative aspects, it showed that FG could cause a significant increase in the proportion of stop decisions [10, 11, 14]. Besides, although FG can effectively reduce the DZ range caused by the yellow light, it enlarges the indecision zone and enormously increases the number of conservative stops and slightly encouraging aggressive passes slightly $[13,15]$. Meanwhile, the presentation of an FG indicator before the $\mathrm{Y}$ indicator considered increasing the complexity of the driver's stop/go decision, leading to repeated decision-making $[15,16]$. 
TABLe 4: Analysis of variance table for speed and distance of FG onset.

\begin{tabular}{|c|c|c|c|c|c|c|}
\hline Variables & Source & Sum of square & $\mathrm{df}$ & Mean square & $F$ & Sig. \\
\hline \multirow{4}{*}{ Speed } & Stop/go & 5816.2 & 1 & 5816.2 & 17.9 & 0.000 \\
\hline & Vehicle type & 7172.9 & 1 & 7172.9 & 22.1 & 0.000 \\
\hline & Area type & 78365.9 & 1 & 78365.9 & 283.8 & 0.000 \\
\hline & Time of the day & 52384.1 & 1 & 52384.1 & 179.2 & 0.000 \\
\hline \multirow{4}{*}{ Distance } & Stop/go & 895878.7 & 1 & 895878.7 & 958.8 & 0.000 \\
\hline & Vehicle type & 0.0 & 1 & 0.0 & 0.0 & 0.998 \\
\hline & Area type & 10098.6 & 1 & 10098.6 & 6.5 & 0.011 \\
\hline & Time of the day & 4374.2 & 1 & 4374.2 & 2.8 & 0.093 \\
\hline
\end{tabular}

TABLE 5: Precision of models for rural intersections and urban intersections.

\begin{tabular}{|c|c|c|c|c|c|}
\hline \multirow{2}{*}{ Models } & & \multirow{2}{*}{ Observed } & \multicolumn{3}{|c|}{ Predicted } \\
\hline & & & Stop & Go & Hit ratios $(\%)$ \\
\hline \multirow{6}{*}{ Rural intersections } & \multirow{3}{*}{ Training } & Stop & 213 & 49 & 81.30 \\
\hline & & Go & 47 & 287 & 85.90 \\
\hline & & Total & $43.60 \%$ & $56.40 \%$ & 83.90 \\
\hline & \multirow{3}{*}{ Test } & Stop & 199 & 68 & 74.50 \\
\hline & & Go & 49 & 274 & 84.80 \\
\hline & & Total & $42 \%$ & $58 \%$ & 80.20 \\
\hline \multirow{6}{*}{ Urban intersections } & \multirow{3}{*}{ Training } & Stop & 61 & 7 & 89.70 \\
\hline & & Go & 2 & 76 & 97.40 \\
\hline & & Total & $43.20 \%$ & $56.80 \%$ & 93.80 \\
\hline & \multirow{3}{*}{ Test } & Stop & 52 & 8 & 86.70 \\
\hline & & Go & 7 & 60 & 89.60 \\
\hline & & Total & $46.50 \%$ & $53.50 \%$ & 88.20 \\
\hline
\end{tabular}

Notably, most of the studies listed above focused on the comparative study of FG installation or not and DZ occurrence and/or stopping probability.

Meanwhile, numerous studies have focused on the modeling of driver's decision-making behavior at the end of the green light [17-20], the most typical of which is the GHM model proposed by Gazis, Herman, and Maraddin [21]. A basic assumption of the GHM model is that the driver decides whether to stop or pass the intersection according to the relationship between the maximum passing distance and the minimum stopping distance at the beginning of the yellow light. Several notable variants have also been reported in the literature [22-25]. The GHM model assumes that all drivers will choose to stop, if possible. But Olson and Rothery [26] found that the yellow light is often used as an extension of the green time phase in the decisionmaking process. Research conducted by May [27] showed that some drivers avoid DZ by accelerating or decelerating. The study of Liu et al. and Wei et al. $[23,28]$ showed that the theoretical hypothesis could lead to differences in driving behavior. In general, the primary defect of the GHM model is the lack of description of the randomness of driving behavior. Because of this disadvantage, some other researchers have attempted to explain DZ behavior through stochastic approaches $[15,29,30]$.

Many studies $[12,16,17,23,31-34]$ believe that the decision-making behavior of drivers is random and obeys a specific probability distribution. The stopping probability, which is described as a function of the speed of the vehicle, the distance to the intersection, or the travel time to the stopline at the beginning of the yellow light, the type of vehicle, etc., is expressed as binary logit model or Bayesian model. Meanwhile, other researchers, such as Rakha et al. [35], Hurwitz et al. [36], Kuo et al. [37], and Moore et al. [38], used fuzzy logic theory to analyze decision-making behavior. It should further point out that the behavioral parameters closely related to decision-making behavior may vary due to the influence of location conditions, driver behavior characteristics, vehicle performance, etc. Also, various potential influencing factors are often related to each other. Some research studies $[16,29,30,39-41]$ carried out in recent years have found that the distribution of decision-making areas may be dynamic, rather than the certainty described by traditional theories.

\section{Data Collection and Reduction}

3.1. Site Descriptions. Five intersections in Shanghai were selected to collect the necessary data, which were a $3 \mathrm{~s}$ FG signal and a $3 \mathrm{~s} \mathrm{Y}$ signal. These intersections are divided into two categories, one with a speed limit of $80 \mathrm{~km} / \mathrm{h}$ and the other with a speed limit of $50 \mathrm{~km} / \mathrm{h}$. The former is mainly located on the roads connecting the urban area and the suburban area, such as Cao'an highway, etc., which has a large traffic flow and a high proportion of large trucks in peak hours. The latter is mainly located in the urban area, and the traffic composition is mostly cars. The main characteristics and conditions of the investigated intersections are shown in Table 1. 


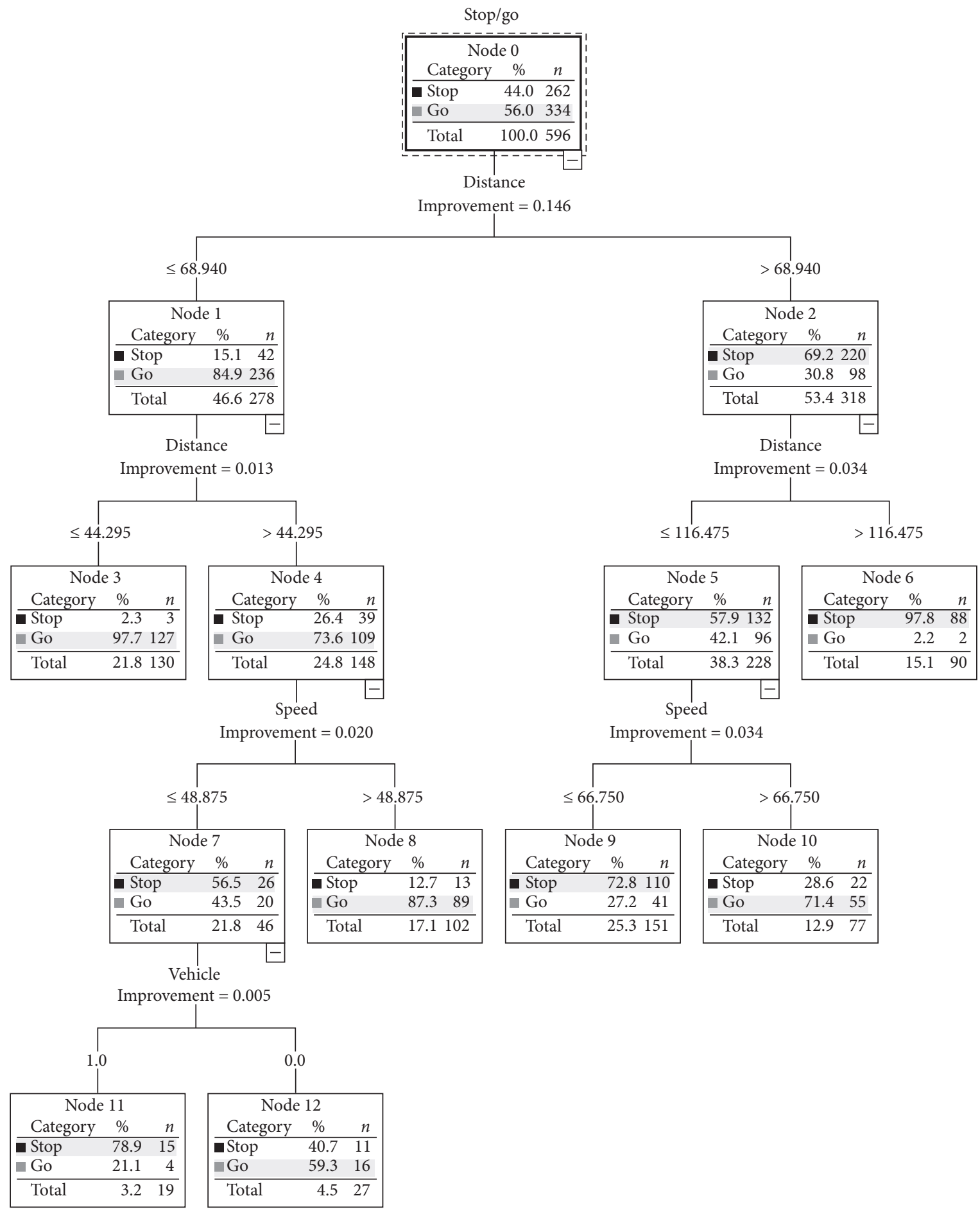

- Stop

- Go

FIgURE 4: DTC analysis results for rural high-speed intersections (training model).

3.2. Field Surveys and Vehicle Trajectory Extraction. We select the sunny weekdays to carry out data collection, trajectory data of vehicles collected by video recording. Two high-definition cameras are required to record synchronously. One of the cameras is installed on the high building near the intersection, which can cover the $80 \mathrm{~m}$ long area upstream of the stop-line, to record the movement trajectory of the whole decision-making process. Another camera is set at the intersection to record traffic signals synchronously. The acquisition of travel trajectories relies on image processing software. It is located by the global coordinates of five related points in the shooting 


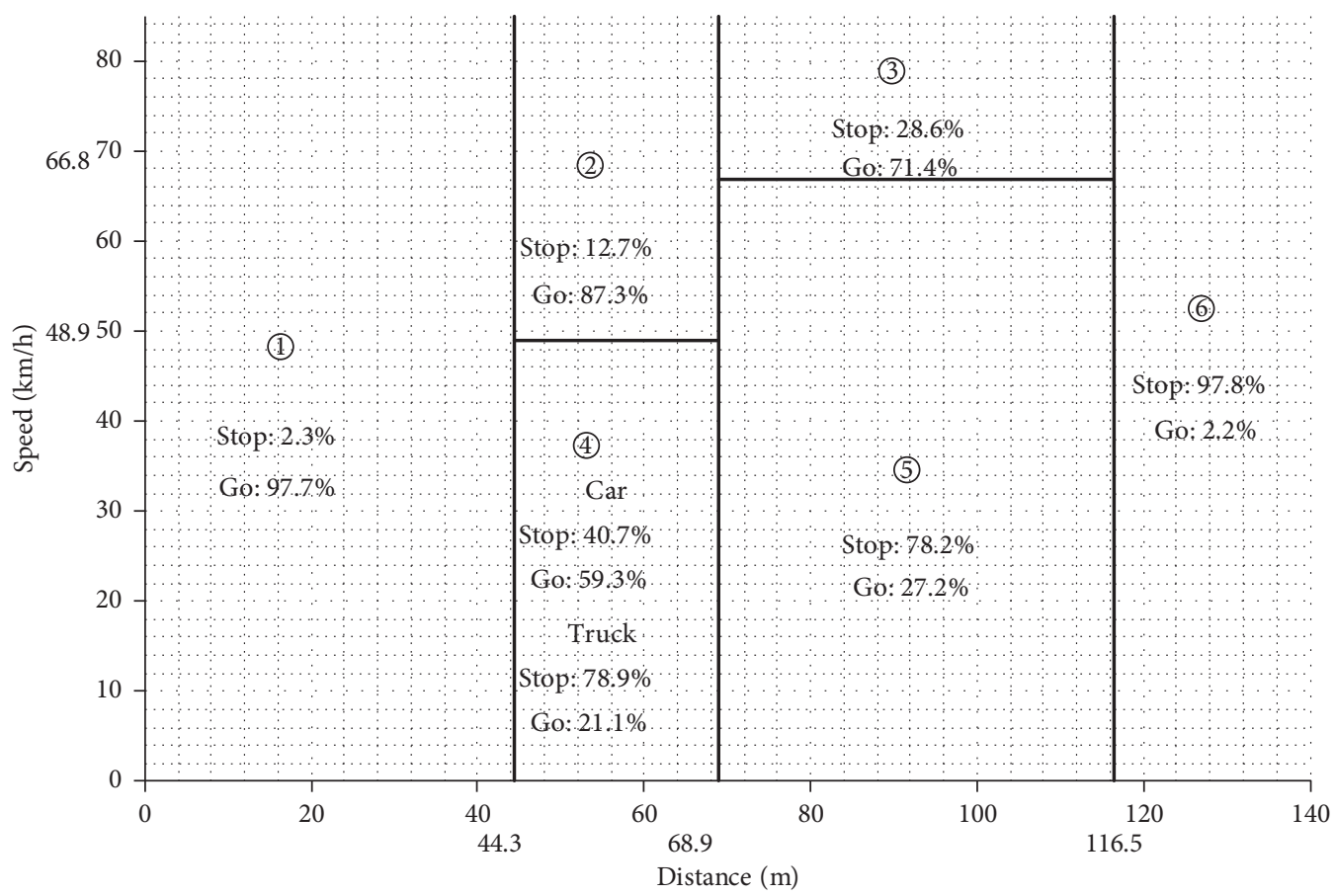

Figure 5: Partition for the stop/go decision model for rural high-speed intersections.

lens. Through residual analysis and $t$-test, it ensured that the accuracy error is not more than $0.15 \mathrm{~m}$ and $0.1 \mathrm{~s}$. The time interval of the software-controlled is $0.1 \mathrm{~s}$. Therefore, matching the trajectory data with the signal change timing, driving behavior parameters such as the speed, acceleration, and deceleration of vehicles, and the position of each step are obtained.

To avoid the influence of preceding vehicles, only the last-to-stop and first-to-go vehicles after the onset of FG are selected for analysis. The last-to-stop vehicle refers to the vehicle selected to stop in front of the stop-line before the start of the red light. The last means that the vehicle is the last vehicle to make a decision in the study period. The first-to-go vehicle refers to the first vehicle passing through the stopline during the study period (i.e., from the end of green light time to the end of yellow light).

Eventually, the trajectories of 1,459 vehicles including 1,186 vehicles (345 trucks and 841 passenger cars) at the rural intersections and 273 vehicles (37 trucks and 236 passenger cars) at the urban intersections were obtained for use in subsequent statistical analysis and model development. As shown in Figure 1, the 1,186 vehicle trajectories collected at the rural intersections included the trajectories of 529 vehicles selected to stop and 657 vehicles selected to pass. In comparison, the 273 trajectories obtained from the urban intersections included the trajectories of 128 vehicles selected to stop and 145 vehicles selected to pass.

\section{Statistical Analysis of Potential Influencing Factors}

Past research has indicated that drivers' stopping decisions at signalized intersections may be influenced by the speed and distance to the stop-line immediately before the phase transition period as well as the vehicle type and time of day $[14,21,22]$. Therefore, statistical analysis was performed to explore the variability of these potential influencing factors as well as their relationships with stop/go decisions in response to the onset of FG.

4.1. Instantaneous Speed at the Start of FG. A statistical analysis of vehicles' instantaneous speeds at the observed approach lane at the start of FG is provided in Table 2 . Comparisons between the rural and urban areas indicate that in both areas, the mean velocities of vehicles making go decisions are higher than those of vehicles making stop decisions. Besides, passenger cars typically have higher rates than trucks in both rural and urban areas. Figure 2 illustrates the distributions of the stop/go decisions relative to various FG-onset speed intervals in rural and urban areas. It finds that in a rural area, if the driver's speed is $60 \mathrm{~km} / \mathrm{h}$, the probabilities of stop and go decisions are equal. The same situation occurs in an urban area when the speed is $50 \mathrm{~km} / \mathrm{h}$, meaning that more truck drivers decide to stop than passenger car drivers given the same approach speed. In Figure 2(b), the situation is similar, with more truck drivers choosing to cross the intersection at a lower speed, which may be safer for large vehicles.

4.2. Distance to the Intersection at the Start of FG. Table 3 presents a statistical summary of distance to the intersection at the start of FG. It is found that the mean value of distance for crossing drivers is shorter than that for stopping drivers. Figure 3 illustrates the distributions of the stop/go decisions 


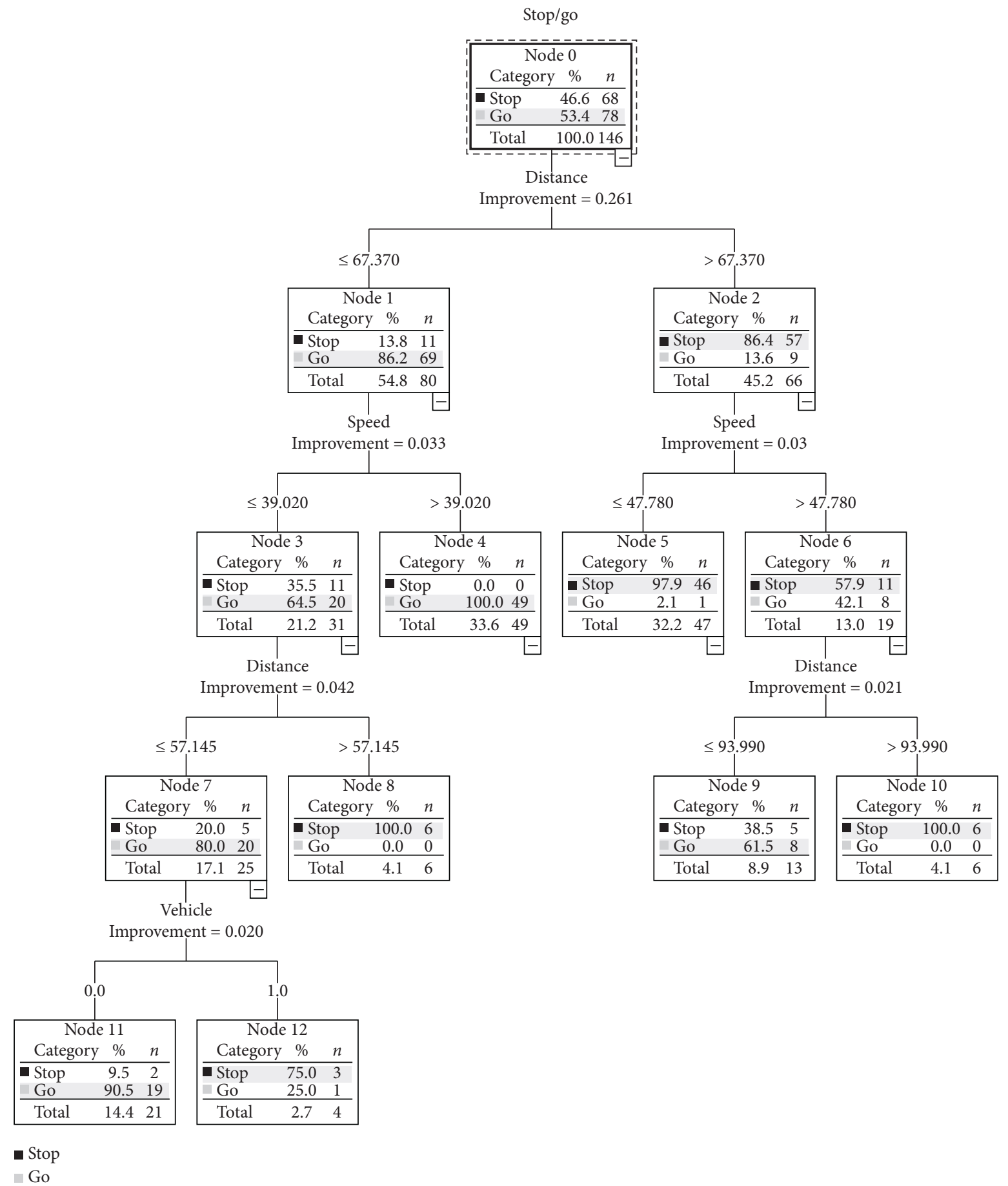

FIGURE 6: DTC analysis results for urban intersections (training model).

relative to various FG-onset distance intervals in rural and urban areas. This figure shows that it is more likely for a driver to make a go decision if he or she is farther from the stop-line, and vice versa. In rural areas, for drivers located in a distance interval of $60-100 \mathrm{~m}$ from the stop-line, the probability of stop decision or pass decision is close to $50 \%$. The same situation is found for a distance interval of $60-80 \mathrm{~m}$ in urban areas. In these distance intervals, it is difficult for drivers to decide whether to stop or go. Moreover, among all drivers who make stop decisions, more truck drivers than passenger car drivers are inclined to stop when the distance to the intersection at the start of FG is shorter than $100 \mathrm{~m}$.

4.3. Analysis of Variance of Potential Influencing Factors. Table 4 shows the analysis of variance (ANOVA) results for the speed and distance at FG onset, where this analysis is conducted to investigate the differences between every pair of factors. The ANOVA results show that multiple traffic factors, 


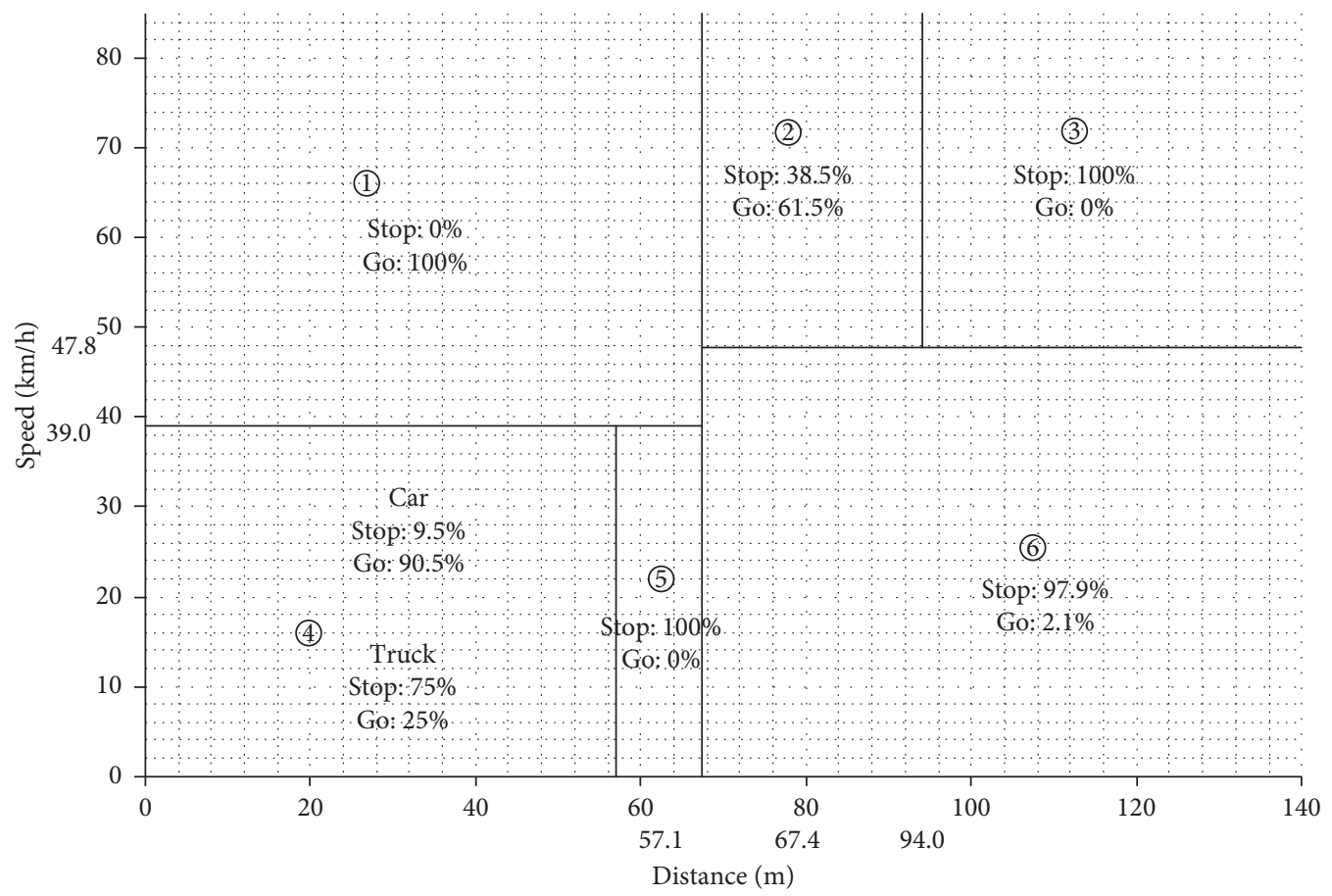

Figure 7: Partition for the stop/go decision model for urban intersections.

including stop/go decisions $(p<0.01)$, vehicle type $(p<0.01)$, and area type $(p<0.01)$, exhibit significant effects with respect to the approach speed of the vehicles at the onset of FG, but only the stop/go decisions $(p<0.01)$ exhibit significant effects with respect to the distance to the stop-line.

\section{Development of Decision Tree Classification Models}

5.1. Decision Tree Models. Because of its nonparametric nature and straightforward interpretation, DTC is proved in the field of traffic engineering [42]. For example, in the traffic safety evaluation, Abellán et al. [43] use DTC to analyze the relationship between stop/go decision, red light violation, and traffic parameters. Some researchers [44, 45] have used DTC methods to explore the relationship between the relevant traffic rules and accident severity.

In this study, the SPSS software package is used for the classification tree analysis. Based on the CART approach, a classification tree model was established, and the Gini criterion (or index) is used as the measure for splitting decisions. Because the data volume is not large, the minimum number of cases for the parent nodes was set to 30 , and the minimum number of instances of the child nodes was set to 10 . Besides, the cross-validation method (with ten folds) was used to evaluate how to extend the tree structure to a larger population. The three variables were expected to be closely related to the driver's stop/go decision, i.e., distance, speed, and vehicle type. The distance variable represents the distance from the vehicle to the stop-line at the start of FG, and the speed variable represents the vehicle's speed at the beginning of FG. Vehicle type variables are divided into two categories: passenger cars and trucks $(0=$ passenger cars and $1=$ trucks $)$.
Table 5 shows the precision of the two developed models. For the rural area model, the training and test accuracies are $83.9 \%$ and $80.2 \%$, respectively, and the prediction of cross behavior is more accurate than that of stopping the behavior. For the urban area model, the training and test model accuracies are $93.8 \%$ and $88.2 \%$, respectively. The model is correctly fitted.

5.2. Result Analysis at Rural High-Speed Intersections. Figure 4 shows the classification tree diagram used for training the stop/go decision model for rural areas.

Figure 5 shows the corresponding partitions, which are much finer-grained than those in Figure 4 . When the distance to the stop-line is shorter than $44.3 \mathrm{~m}$ or more prolonged than $116.4 \mathrm{~m}$, most of the vehicles make the same decision. When the distance is between $44.3 \mathrm{~m}$ and $116.4 \mathrm{~m}$, the approach speed effects on the stop/go decision.

(i) For vehicles at FG-onset distances of less than $44.3 \mathrm{~m}, 97.7 \%$ of drivers will cross the intersection, as shown in Zone 1.

(ii) By contrast, for vehicles at FG-onset distances of more than $116.5 \mathrm{~m}$, the percentage of drivers that will cross the intersection is only $2.2 \%$, whereas most drivers (97.8\%) will stop, as shown in Zone 6.

(iii) For vehicles at FG-onset distances between $44.3 \mathrm{~m}$ and $68.9 \mathrm{~m}$, the most critical factor affecting the drivers' stop/go decisions is speed. For vehicles with FG-onset rates higher than $48.9 \mathrm{~km} / \mathrm{h}$, most drivers $(87.3 \%)$ will cross the intersection. By contrast, for vehicles with FG-onset speeds below than $48.9 \mathrm{~km} / \mathrm{h}$, the vehicle type plays an essential role in the stop/go 

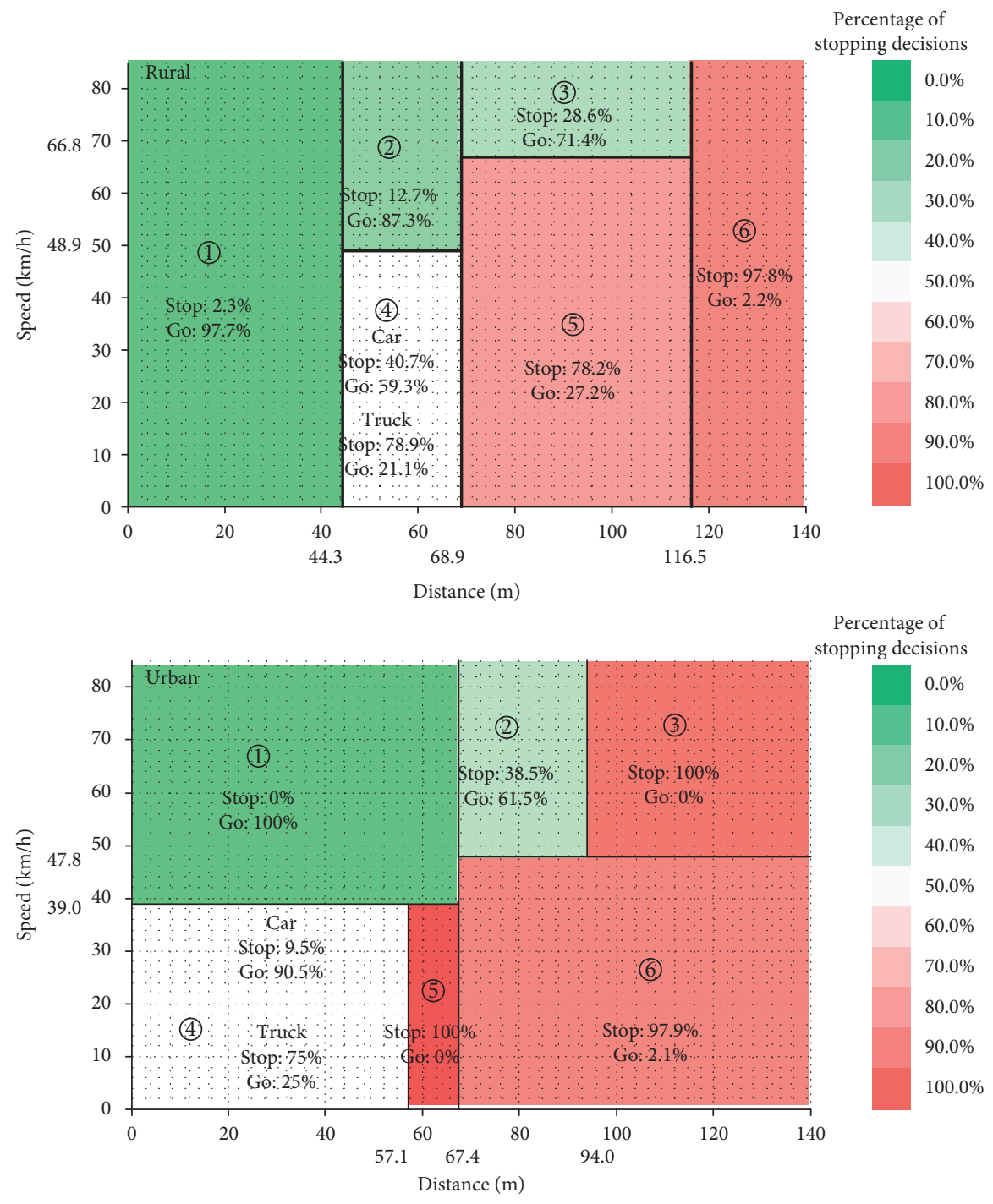

Figure 8: Comparison of the stop/go decision between rural and urban intersections.

decision. Trucks are more likely to stop than passenger cars. These behaviors above and below $48.9 \mathrm{~km} / \mathrm{h}$ correspond to Zones 2 and 4, respectively.

(iv) Finally, for vehicles at FG-onset distances between $68.9 \mathrm{~m}$ and $116.5 \mathrm{~m}$, the approach speed again plays a critical role. For vehicles with FG-onset rates higher than $66.8 \mathrm{~km} / \mathrm{h}$, most of the drivers (71.4\%) will cross the intersection. However, for vehicles with FG-onset speeds below than $66.8 \mathrm{~km} / \mathrm{h}$, most drivers $(72.8 \%)$ will stop, as indicated in Zone 5.

5.3. Result Analysis at Urban Intersections. Figure 6 shows the classification tree diagram used to train the stop/go decision model for urban areas. Similar to Figure 5, the corresponding partitions for the tree in Figure 6 are drawn in Figure 7. This graph is divided into six zones:

(i) As shown in Figure 7, all vehicle drivers in Zone 1 will choose to cross the intersection, while most drivers (97.9\%) in Zone 6 will stop, since the distance to the stop-line is more significant than a particular threshold value, in this case, $67.4 \mathrm{~m}$.

(ii) A situation similar to that found for rural intersections occurs in the classification tree for urban intersections. The vehicle type plays a vital role in the drivers' stop/go decisions for vehicles in Zone 4, where FG-onset distances are less than $57.1 \mathrm{~m}$, and the FG-onset speeds are below $39 \mathrm{~km} / \mathrm{h}$.

(iii) For vehicles at FG-onset distances between $57.1 \mathrm{~m}$ and $67.3 \mathrm{~m}$ with FG-onset speeds below $39 \mathrm{~km} / \mathrm{h}$, all drivers will choose to stop (corresponding to Zone 5 in Figure 7).

(iv) For vehicles with FG-onset speeds higher than $47.8 \mathrm{~km} / \mathrm{h}$, there are two different situations: for vehicles at FG-onset distances between $67.4 \mathrm{~m}$ and $94 \mathrm{~m}, 61.5 \%$ of drivers will cross the intersection, while for vehicles at FG-onset distances greater than $94 \mathrm{~m}, 100 \%$ of drivers will choose to stop, as indicated in Zones 2 and 3, respectively. 
5.4. Comparisons of Rural High-Speed Intersections and Urban Intersections. The percentages of stop decisions are shown through a color scale in Figure 8. This figure illustrates that drivers tend to make stop decisions when the vehicle is farther from the stop-line, and the approach speed is higher, whether the intersection is in a rural or urban area.

However, there are some differences between rural highspeed intersections and urban intersections:

(1) Truck drivers are more conservative at urban intersections, especially when they are nearer to the stop-line at modestly low speeds (below $39 \mathrm{~km} / \mathrm{h}$ ). Because of the higher speed limit at rural high-speed intersections, such conservative decision behavior emerges at these intersections at greater distances of $44.3 \sim 68.9 \mathrm{~m}$ and speeds below $48.9 \mathrm{~km} / \mathrm{h}$.

(2) Due to the difference between the speed limits, most drivers tend to stop rather than cross at urban intersections when the distance exceeds $57.1 \mathrm{~m}$ while at rural high-speed intersections, this distance threshold increases to $68.9 \mathrm{~m}$.

(3) When the vehicles are at a sufficiently far distance, such as $116.5 \mathrm{~m}$ from the stop-line at a rural intersection, nearly all drivers choose to stop independent of the approach speed. However, this value is much smaller, specifically, $94 \mathrm{~m}$ at an intersection.

\section{Conclusions and Future Works}

This study generated two models: the first illustrates the conditions affecting stop/go decisions in rural areas, and the other explains the corresponding requirements in urban areas. The data analysis indicates that the vehicle speed and distance to the stop-line when FG is on as well as the vehicle type are the most significant factors affecting the driver's stop/go decision in both rural and urban areas. The normalized importance of the distance variable is $100 \%$ for both types of sites. In rural areas, the normalized importance of speed is higher than that in urban areas. For vehicles at FGonset distances between $68.9 \mathrm{~m}$ and $116.5 \mathrm{~m}$, the rate becomes the critical factor affecting drivers' behavior. The probability of stop decision is almost equal to that of pass decision, both of which are close to 0.5 . The corresponding distance interval in urban areas is between $67.4 \mathrm{~m}$ and $94 \mathrm{~m}$. An interesting finding of this study is that under the same conditions, regardless of whether the intersection is in a rural or urban area, most truck drivers tend to park more than car drivers.

This study presents a novel way to analyze stop/go decisions. The tree-based model provides a good verbal explanation, which makes it easier to examine other conditions. The classification tree provides a simple method to model the driver's behavior without any normal assumptions. The stop/go decision-making model based on DTC developed in this study can be used to improve the driver behavior model embedded in microscopic traffic simulation software.

\section{Data Availability}

The data used to support the findings of this study included in the article.

\section{Conflicts of Interest}

The authors declare that there are no conflicts of interest regarding the publication of this paper.

\section{Acknowledgments}

This study was supported by the Natural Science Foundation of Zhejiang Province (no. LQ19E080003), Philosophy and Social Science Program of Ningbo (no. G20-ZX37), Natural Science Foundation of Ningbo (nos. 2018A610127 and 2019A610044), and The Opening Foundation of the State Key Laboratory for Management and Control of Complex Systems (no. 20190102).

\section{References}

[1] K. Tang, Y. Xu, P. Wang, and F. Wang, "Impacts of flashing green on dilemma zone behavior at high-speed intersections: empirical study in China," Journal of Transportation Engineering, vol. 141, no. 7, Article ID 04015005, 2015.

[2] S. Dong, J. Zhou, L. Zhao, K. Tang, and R. Yang, "Feasibility analysis of phase transition signals based on e-bike rider behavior," Advances in Mechanical Engineering, vol. 7, no. 11, pp. 1-18, 2015.

[3] S. Dong, J. Zhou, and S. Zhang, "Determining E-bike drivers' decision-making mechanisms during signal change interval using the hidden Markov driving model," Journal of Advanced Transportation, vol. 2019, pp. 1-10, 2019.

[4] K. Tang, Y. Xu, F. Wang, and T. Oguchi, "Exploring stop-go decision zones at rural high-speed intersections with flashing green signal and insufficient yellow time in China," Accident Analysis \& Prevention, vol. 95, pp. 470-478, 2016.

[5] P. Koonce and L. Rodegerdts, Traffic Signal Timing Manual (No. FHWA-HOP-08-024), Federal Highway Administration, Washington, DC, USA, 2008.

[6] G. Britain and T. A. Unit, General Principles of Traffic Control by Light Signals, Department for Transport, London, UK, 2006.

[7] C. A. O'Flaherty, Transport Planning and Traffic Engineering, CRC Press, Boca Raton, FL, USA, 2018.

[8] X. Dou, X. Guo, X. Gong, and J. Yang, "Evaluating impacts of flashing green before amber on drivers' stop/cross decisions at signalized intersections in China: an empirical approach and comparative study," in Proceedings of the 92nd Transportation Research Board Annual Meeting, Washington, DC, USA, January 2013.

[9] M. Becker, A Study of the Effect of a "Flashing Green" Phase in Traffic Signals at Urban Intersections, Technion Research and Development Foundation Ltd., Haifa, Israel, 1971.

[10] D. Mahalel and D. M. Zaidel, "Safety evaluation of a flashinggreen light in a traffic signal," Traffic Engineering and Control, vol. 26, no. 2, pp. 79-81, 1985.

[11] C. Newton, R. N. Mussa, E. K. Sadalla, E. K. Burns, and J. Matthias, "Evaluation of an alternative traffic light change anticipation system," Accident Analysis \& Prevention, vol. 29, no. 2, pp. 201-209, 1997. 
[12] Q. Zeng, W. Gu, X. Zhang, H. Wen, J. Lee, and W. Hao, "Analyzing freeway crash severity using a Bayesian spatial generalized ordered logit model with conditional autoregressive priors," Accident Analysis \& Prevention, vol. 127, pp. 87-95, 2019.

[13] H. Köll, M. Bader, and K. W. Axhausen, "Driver behaviour during flashing green before amber: a comparative study," Accident Analysis \& Prevention, vol. 36, no. 2, pp. 273-280, 2004.

[14] R. Factor, J. N. Prashker, and D. Mahalel, “The flashing green light paradox," Transportation Research Part F: Traffic Psychology and Behaviour, vol. 15, no. 3, pp. 279-288, 2012.

[15] K. Tang, Y. Xu, and F. Wang, "Dilemma zone occurrences at the rural high-speed intersections with flashing green and insufficient yellow time in China," in Proceedings of the 94th Transportation Research Board Annual Meeting, Washington, DC, USA, January 2015.

[16] F. Wang, K. Tang, Y. Xu, J. Sun, and K. Li, "Modeling risky driver behavior under the influence of flashing green signal with vehicle trajectory data," Transportation Research Record: Journal of the Transportation Research Board, vol. 2562, no. 1, pp. 53-62, 2016.

[17] K. Long, L. D. Han, and Q. Yang, "Effects of countdown timers on driver behavior after the yellow onset at Chinese intersections," Traffic Injury Prevention, vol. 12, no. 5, pp. 538-544, 2011.

[18] F. Chen, M. Song, and X. Ma, "Investigation on the injury severity of drivers in rear-end collisions between cars using a random parameters bivariate ordered probit model," International Journal of Environmental Research and Public Health, vol. 16, no. 14, p. 2632, 2019.

[19] X. Zhu, Z. Dai, F. Chen, X. Pan, and M. Xu, "Using the visual intervention influence of pavement marking for rutting mitigation-part II: visual intervention timing based on the finite element simulation," International Journal of Pavement Engineering, vol. 20, no. 5, pp. 573-584, 2019.

[20] G. Wu, F. Chen, X. Pan, M. Xu, and X. Zhu, "Using the visual intervention influence of pavement markings for rutting mitigation-part I: preliminary experiments and field tests," International Journal of Pavement Engineering, vol. 20, no. 6, pp. 734-746, 2019.

[21] D. Gazis, R. Herman, and A. Maradudin, "The problem of the amber signal light in traffic flow," Operations Research, vol. 8, no. 1, pp. 112-132, 1960.

[22] M. S. Chang, C. J. Messer, and A. J. Santiago, "Timing traffic signal change intervals based on driver behavior," Transportation Research Record, vol. 1027, pp. 20-30, 1985.

[23] C. Liu, R. Herman, and D. C. Gazis, "A review of the yellow interval dilemma," Transportation Research Part A: Policy and Practice, vol. 30, no. 5, pp. 333-348, 1996.

[24] J. Zhou, Y. Guo, S. Dong, M. Zhang, and T. Mao, "Simulation of pedestrian evacuation route choice using social force model in large-scale public space: comparison of five evacuation strategies," PLoS one, vol. 14, no. 9, pp. 1-18, 2019.

[25] J. Zhou, X. Mao, Y. Wang, M. Zhang, and S. Dong, "Risk assessment in urban large-scale public spaces using Dempster-shafer theory: an empirical study in Ningbo, China," International Journal of Environmental Research and Public Health, vol. 16, no. 16, p. 2942, 2019.

[26] P. L. Olson and R. W. Rothery, "Driver response to the amber phase of traffic signals," Operations Research, vol. 9, no. 5, pp. 650-663, 1961.

[27] A. D. May Jr., "Clearance interval at traffic signals," Highway Research Record, vol. 221, pp. 41-71, 1968.
[28] H. Wei, Z. Li, P. Yi, and K. R. Duemmel, "Quantifying dynamic factors contributing to dilemma zone at high-speed signalized intersections," Transportation Research Record: Journal of the Transportation Research Board, vol. 2259, no. 1, pp. 202-212, 2011.

[29] J. N. Prashker and D. Mahalel, "The relationship between an option space and drivers' indecision at signalized intersection approaches," Transportation Research Part B: Methodological, vol. 23, no. 6, pp. 401-413, 1989.

[30] P. Li and M. Abbas, "Stochastic dilemma hazard model at high-speed signalized intersections," Journal of Transportation Engineering, vol. 136, no. 5, pp. 448-456, 2010.

[31] P. Papaioannou, "Driver behaviour, dilemma zone and safety effects at urban signalised intersections in Greece," Accident Analysis \& Prevention, vol. 39, no. 1, pp. 147-158, 2007.

[32] Q. Zeng, Q. Guo, S. C. Wong, H. Wen, H. Huang, and X. Pei, "Jointly modeling area-level crash rates by severity: a Bayesian multivariate random-parameters spatio-temporal Tobit regression," Transportmetrica A: Transport Science, vol. 15, no. 2, pp. 1867-1884, 2019.

[33] Y. Guo, Z. Li, P. Liu, and Y. Wu, "Modeling correlation and heterogeneity in crash rates by collision types using full Bayesian random parameters multivariate Tobit model," Accident Analysis \& Prevention, vol. 128, pp. 164-174, 2019.

[34] Y. Guo, P. Liu, Y. Wu, and M. Yang, "Traffic conflict model based on Bayesian multivariate Poisson-lognormal normal distribution," China Journal of Highway and Transport, vol. 31, no. 1, pp. 101-109, 2018.

[35] H. Rakha, I. El-Shawarby, and J. R. Setti, "Characterizing driver behavior on signalized intersection approaches at the onset of a yellow-phase trigger," IEEE Transactions on Intelligent Transportation Systems, vol. 8, no. 4, pp. 630-640, 2007.

[36] D. S. Hurwitz, M. A. Knodler Jr., and B. Nyquist, "Evaluation of driver behavior in type II dilemma zones at high-speed signalized intersections," Journal of Transportation Engineering, vol. 137, no. 4, pp. 277-286, 2010.

[37] K. Y. Kuo, Y. J. Chen, and R. C. Hwang, "Calculation of the change and clearance intervals of traffic signal by fuzzy logic system," in Proceedings of the Meeting of Joint Conference of International Computer Symposium, Kaohsiung, Taiwan, 1996.

[38] D. Moore and D. S. Hurwitz, "Fuzzy logic for improved dilemma zone identification," Transportation Research Record: Journal of the Transportation Research Board, vol. 2384, no. 1, pp. 25-34, 2013.

[39] Y. J. Moon and F. Coleman III, "Dynamic dilemma zone based on driver behavior and car-following model at highwayrail intersections," Transportation Research Part B: Methodological, vol. 37, no. 4, pp. 323-344, 2003.

[40] K. Tang, S. Dong, F. Wang, Y. Ni, and J. Sun, "Behavior of riders of electric bicycles at onset of green and yellow at signalized intersections in China," Transportation Research Record: Journal of the Transportation Research Board, vol. 2317, no. 1, pp. 85-96, 2012.

[41] N. Elmitiny, X. Yan, E. Radwan, C. Russo, and D. Nashar, "Classification analysis of driver's stop/go decision and redlight running violation," Accident Analysis \& Prevention, vol. 42, no. 1, pp. 101-111, 2010.

[42] L. Breiman, Classification and Regression Trees, Routledge Publisher, Taylor \& Francis Group, Abingdon-on-Thames, UK, 2017.

[43] J. Abellán, G. López, and J. de Oña, “Analysis of traffic accident severity using decision rules via decision trees," Expert 
Systems with Applications, vol. 40, no. 15, pp. 6047-6054, 2013.

[44] J. Zhou, Y. Wu, X. Mao, S. Guo, and M. Zhang, "Congestion evaluation of pedestrians in metro stations based on normalcloud theory," Applied Sciences, vol. 9, no. 17, p. 3624, 2019.

[45] A. T. Kashani and A. S. Mohaymany, "Analysis of the traffic injury severity on two-lane, two-way rural roads based on classification tree models," Safety Science, vol. 49, no. 10, pp. 1314-1320, 2011. 